\title{
Design of Children Entertainment Facilities
}

\author{
Mei Li \\ School of Architecture and Art Design \\ Hebei University of Technology \\ \#2-107 Yijiangli, Minquanmen Hebei District, Tianjin 300250, China \\ E-mail: beautyli83@163.com
}

\begin{abstract}
In this paper, mainly through analysis of problems on existing children entertainment facilities and the impact of children entertainment facilities on children psychological development, it is to be discussed about the key point of children entertainment facilities design.
\end{abstract}

Keywords: Children, Entertainment facilities, Development, Design

\section{Problems on existing children entertainment facilities}

\subsection{Monotone design style of children entertainment facilities}

The existing children entertainment facilities are limited to swing, carousel and such simple amusement facilities. Only few facilities adopt complex techniques which are good for the development of children. The attention focused on the design of children entertainment facilities is far from enough. Due to lack of variety, children lose their interest in the facilities.

\subsection{Safety risk in existing children entertainment facilities}

The outdoor facilities must withstand sunshine and wind. However, because of some ill-conceived design, some materials used in the facilities are working beyond their use limits; some paintwork flakes and some materials get rusted which affect the strength of material severely.

\subsection{Less opportunities of communication}

Communication is essential to people especially of growing-up children. Skills of cooperation and speaking will be well developed in communication. Therefore, it should be considered in design of children entertainment facilities to create a communication environment.

\subsection{Ill-conceived placement of children entertainment facilities}

For example placing facilities in low air quality places will cause harm to children's health.

\section{The effects of children entertainment facilities on children's mental development}

Pre-school children may spontaneously get to know the things that they are interested in. Facilities games contain numerous categories, and during which children will accumulate knowledge and experience, develop the level of mentality by communicating and self-searching. From the following we can find out the relationship between children facilities games and the development of children psychology.

\subsection{Children entertainment facilities and the development of children's ability of concentration}

Starting at the early age of people, concentration is a kind of focus of certain objects, which help to observe the surroundings. The ability of concentration is a key aspect influencing the children's intelligence. There are many fresh, intense and exciting changes in the facilities games, which catch children's intention. There are many positive effects of facilities games on the practicing concentration, such as enlarging children's life range, arising the interest and curiosity, making children like to imitate, to ask and to move, which attract the concentration of children and extend the time of it.

\subsection{Children entertainment facilities and the development of children's ability of observation}

The cultivation of observation ability is one of the significant contents of children's sense development, which is a purposeful percipience activity. Research shows that observation ability starts at the age of two to three, as children grow, the time and summarization of their observation will grow too. Facilities games echo with observation, on one hand, observation guarantee the process of the games; on the other hand, facilities games also recreate the environment for observation. During the games, children not only observe the facility, but also the environment and the objects, and find the inner-connection, which has significant meaning on children's intelligence and mentality development. 


\subsection{Children entertainment facilities and the development of children's memory}

Memory is the psychological process of accumulating and keeping individual experience in human brain, whose significance is to help people solve issues based on experience. Psychology research shows that it is much easier for children to remember things with strong impression, in other words, the more interest children have, the more things they can remember; and children entertainment facilities indeed provide a platform to experience and practice memory.

Children recall things deliberately in the games. As most of the facilities games reflect issues that children have undergone before, so that children need to recollect what they have done, which process makes a lot contribution to strengthening memory. Meanwhile, it is children's instinct that makes them like facilities games, and they will also practice their memory, and improve it in the game.

\subsection{Children entertainment facilities and the development of children's thinking ability}

Thinking ability is the core of children's intelligence. Through language, image and action, thinking is the reflection of the object.

Developing from primary to senior, children's intellect is encouraged by the entertainment facilities, mainly because the process of facilities games is the process of active recreation rather than the repeat of last experience. There are more new elements in the facilities games, so that Children can show more divergent thinking in the games and during which children's ability of analyzing, logic thinking and initial idea can also be cultivated. Children's thinking in the games cannot be separated from the game situation, by which it is also affected and confined.

\subsection{Children entertainment facilities and the development of children's imagination}

Imagination is an indispensable factor for people to know and develop the world. Without which, there will be no creation and no development. Therefore, Imagination is crucial to children as it is the main part displaying in their games. Research shows that imagination can help children solve problems more actively. Children should be cultivated the ability of solving problems rather than be told what to do, as leading by the curiosity, children show more interest in things they never done before and willing to try. During games provided by entertainment facilities, children may encounter a lot problem that happening not only in games but also in our daily life, the interest to the game will light the curiosity in their heart and push them to think any ways that can solve the issues.

The experience can be seen as a tool, it can help in your whole life. As in the situation of children's psychology structure and knowledge level, their actions are full of recreation and specification. Diversity is the reason for children to keep their interest and participation. The internal diversity showing between the game unit and the change of children's concentration leading to the birth of imagination, which we can see as the embryo of children's creation.

\subsection{Children entertainment facilities and the development of children's language ability}

Facilities games are good to the development of children's language ability, and which create more opportunity of communication and cooperation. During the games, children need language to communicate. Furthermore, facilities games can also enrich the topic of children's conversation, and help to improve communicating skills.

\subsection{Children entertainment facilities and the development of children's personality}

Entertainment facilities, with their ever fascinating charm to children, help children developing healthy personality, as they convey human loving and caring feelings. Besides, these facilities provide areas for children to communicate with each other. During the process of playing around the facilities, such qualities as respecting, caring, friendliness and sharing are developed.

\subsection{Children entertainment facilities and the development of children's social characters}

Children's social characters are gradually formed and developed through education and social influence. Social character development is a life-long process, which has different task and content due to age differences. And social qualities are developed at different stages. Before the age of seven, social skills and self-consciousness are gradually forming; sympathy and altruism are evenly developing. From three to four years is the crucial period to develop social reliance. And five to six years is the key time to develop social adaptation skills and world knowledge.

Factors to influence children's development of social characters could form into a complicated system of social culture and social interaction. Among these factors, the influence of game-playing should not be overlooked. Playing games is one of the main channels for children to contact social life. And it is also a role-play-game rules as an imitation of social rules. Thus facilities games will play an important part in developing children's social characters with their vivid images, modern sense and strong influence.

Therefore, facilities games are important for children's growth. Games are not only means for children to know the world, windows to observe life, sources to accumulate knowledge and experience, but also effective ways for them to explore the world around. They help a lot in children's psycho-development. 


\section{Factors in designing of children entertainment facilities based on the development of children's behaviors}

\subsection{Safety}

Safety is an issue that should be deeply considered while designing children entertainment facilities. Safety of body is usually considered in previous designs. However, mental safety should also not be neglected, especially for pre-school children. To create one safe and ease playing environment is a prerequisite of the cognitive development of their positive tendency to explore.

Since children are interested in playing, not aware of self-protection and easy to be injured, the facilities should be safe, considering the characters of children. For instance, the surface of facilities should be smooth, without sharp corners; the structure should be safe, rational, stable and with skid proof protection. For mental safety, it can be realized through choosing warm color which will make children feel warm and safe. With the feeling of safe, children will be naturally integrated with the gaming environment and positively experience the joy of gaming.

\subsection{Combination}

It is not only simple superimposition of form or quantity but also the combination of function. The children entertainment facility should be a complete system which integrates all kinds of aspects. Each aspect has its own value and the purpose of combination is to achieve its maximum efficacy, reflect the principle of diversity, provide different game activities and increase opportunities for the game. So that children's attention will be focused on games, their studying and thinking potentiality will be well developed.

\subsection{Interest/ fascination}

Because of children's natural instincts, they like entertainment facilities which are full of vitality and affinity. Thereof, the appearance, color and material of entertainment facilities should be in compliance with the characteristics of children's psychological development. Those facilities which are colorful, in exaggerated form or in the shape of cartoon would normally stimulate children's interest. They can get the spirit of good to meet their psychological needs.

\subsection{Coordination}

With environment: this should perform in two areas, one of which is coordinating the natural environment. Children entertainment facilities should be designed in consideration of natural environment, harmony and integration. With dry cold climate, material should be chosen on the basis of wood, and with the warm wet climate, attention should be paid to rust-proof material, and more use of plastics or stainless steel. The second is the coordination of gaming environment. Plan and design a children's venue and arouse the children's nature of "playing". This will help children full of creativity and competitiveness, and improve their cognitive ability.

\subsection{Development}

It should be considered from the children's physical and mental development, social development and the development of the game. Age or the environment changes, so that children playing nature gradually fades. Children's favorite game is outdoor playing. The game is their work. Survey found that nowadays the number of children that do not know how to play is increasing. TV, electric toys, will weaken children's expression ability and the ability to accept feelings while helping children improve the response rate. How to design a perfect entertainment facility that suits contemporary children's physical and emotional development is the problem to be solved.

\section{Summary}

Children are the future of human development, and designing for them is even more important. Children entertainment facilities are the main component of children playing environment, therefore its significance can not be ignored. To achieve the purpose of entertaining, the designer should change their view, considering from the perspective of children, to design real-entertainment, healthy, educational facilities.

\section{References}

Zhu, Tang chun. (2004). Pieces gardens and facilities-Children entertainment facilities. China Building Industry Publishing House.

Lin, Chong de. (2002). Developmental psychology. Zhe Jiang Education Publishing House.

Cao, Zhong ping. (2000). The research in the cognitive psychology of the children's game. Pre-school education research, 2000, III.

Xia, Miao. (2002). Grow wings: pioneering children's imagination and create space. China Light Industry Publishing House.

Qian, Tao \& Zhou, Hong sheng. (2002). Considering on the exploitation and design of the children's toys. [Online] Available: http://www.dolcn.com/d/digest/20020712102228.html (July 2, 2008). 